\title{
Research and Exploration on Innovative Practice Ability Training Mode of Professional Degree Graduate Students Majoring in Electrical Engineering
}

\author{
Fengli Jiang \\ College of Information and Electrical Engineering Shenyang \\ Agricultural University \\ Shenyang, China \\ Lisi Fu \\ College of Information and Electrical Engineering Shenyang \\ Agricultural University \\ Shenyang, China
}

\begin{abstract}
The reform for the practice ability of professional degree graduate students is the important guarantee to improve the quality of graduate student education and cultivate the applied talents. Under the circumstance that the global construction of smart grid and power companies desiring for skilled personnel, Shenyang Agricultural University carried out innovative practice ability training mode for electrical engineering professional degree graduate students, actively. The school took many steps to strengthen the professional degree graduate students' innovative ability training, such as developing a reasonable training program, constructing practical teaching system and establishing wide range standards for academic dissertation and other measures. And that achieved good results.
\end{abstract}

Keywords - the professional degree graduate students; practice ability; innovation ability; training mode

\section{INTRODUCTION}

In 2009, the Ministry of Education increased full-time professional degree graduate students enrollment based on the original graduate enrollment plan. The main admission objects are the fresh graduates ${ }^{[1]}$. And then the full-time professional degree graduate education has developed rapidly, its size and connotation have a leap-forward development. The phenomenon shows that China's graduate student training structure is changed from the research-oriented to the application-based.

The professional degrees are branched from the academic degrees for the needs of social professionalism ${ }^{[2]}$. Different from the academic degrees emphasis on theoretical research, "Professional" and "applied" is the biggest feature of the professional degrees ${ }^{33}$. However, the training time for full-time professional degrees graduate education is shorter, and whose training mode is similar to the academic graduate training mode, especially practicality is not prominent.

\author{
Tongyu $\mathrm{Xu}^{*}$ \\ College of Information and Electrical Engineering Shenyang \\ Agricultural University \\ Shenyang, China \\ Chunling Chen \\ College of Information and Electrical Engineering Shenyang \\ Agricultural University \\ Shenyang, China
}

In view of the above problems, Shenyang Agricultural University has carried on the thorough exploration to the reform of training mode for electrical engineering professional degree graduate students. The object is to cultivate the application of talents for power companies and improve the quality of employment, based on enhancing the quality of graduate tutor business, developing targeted training programs, strengthening the quality of dissertation, perfecting the practice teaching system and improving the quality of classroom teaching.

\section{DEVELOP A PRACTICE-ORIENTED TRAINING PROGRAM}

The training program should take the practical application of electric power enterprises as the guiding and the professional demand as the goal, and the improvement of the comprehensive quality and the knowledge application ability as the core. The training program usually includes training objectives, research direction, training methods, curriculum and assessment methods, degree grant requirements and other parts. According to market research and professional ability analysis, our school revised the personnel training objectives and research direction for the professional needs. We set courses fully considered the basic knowledge of undergraduate study and followed the actual development of power systems and trends. For example, "Power System Analysis" is the basic course for the electrical engineering undergraduate students. Therefore, we can set "Advanced Power System Analysis", "Modern Power System Analysis", "New Energy Power Generation Technology", "Smart Grid" and other courses in the graduate period. This will be able to respond to the basic knowledge and with strong cohesion, so that the students can master the knowledge and skills in power specific areas even keeping up with the forefront development. In addition, we also established the corresponding vocational qualification examination courses. 


\section{ESTABLISH A HIGH-QUALITY PROFESSIONAL PRACTICE, AND THEN BUILD A PRACTICAL TEACHING SYSTEM}

On one hand, the full-time professional degree graduate students are almost from fresh graduates, so they are lack of practical experience. On the other hand, professional practice is an important part for a graduate student to supplement practical experience and to meet the future career needs. It also directly related to the course learning effectiveness of the full-time professional graduate students and their thesis quality. With personal experience, the graduate students will understand and accept the professional knowledge easier. In addition, professional practice is also the main source for the full-time professional degree graduate students to obtain a dissertation topic and related material. Therefore, it can be said that grasping the professional practice is the key to achieve training objectives for full-time professional degree graduate students and transform the degree categories successfully.

Based on the rural intelligent distribution network and distributed generation virtual experiment teaching center and off - campus practice base, a complete practical teaching system is established, and it is improved continuously in the teaching practice. The practical teaching system includes the experimental platform, practice contents, teacher guarantee, and evaluation mechanism. The four sub-system elements constitute the overall function of the teaching system. In the system the experimental platform is the prerequisite basis, the practice contents are the core, the teacher guarantee is the teaching guarantee, and the evaluation mechanism is the feedback mechanism. Then the four sub-systems complement each other, through the whole process of personnel training. The architecture is shown in figure 1.

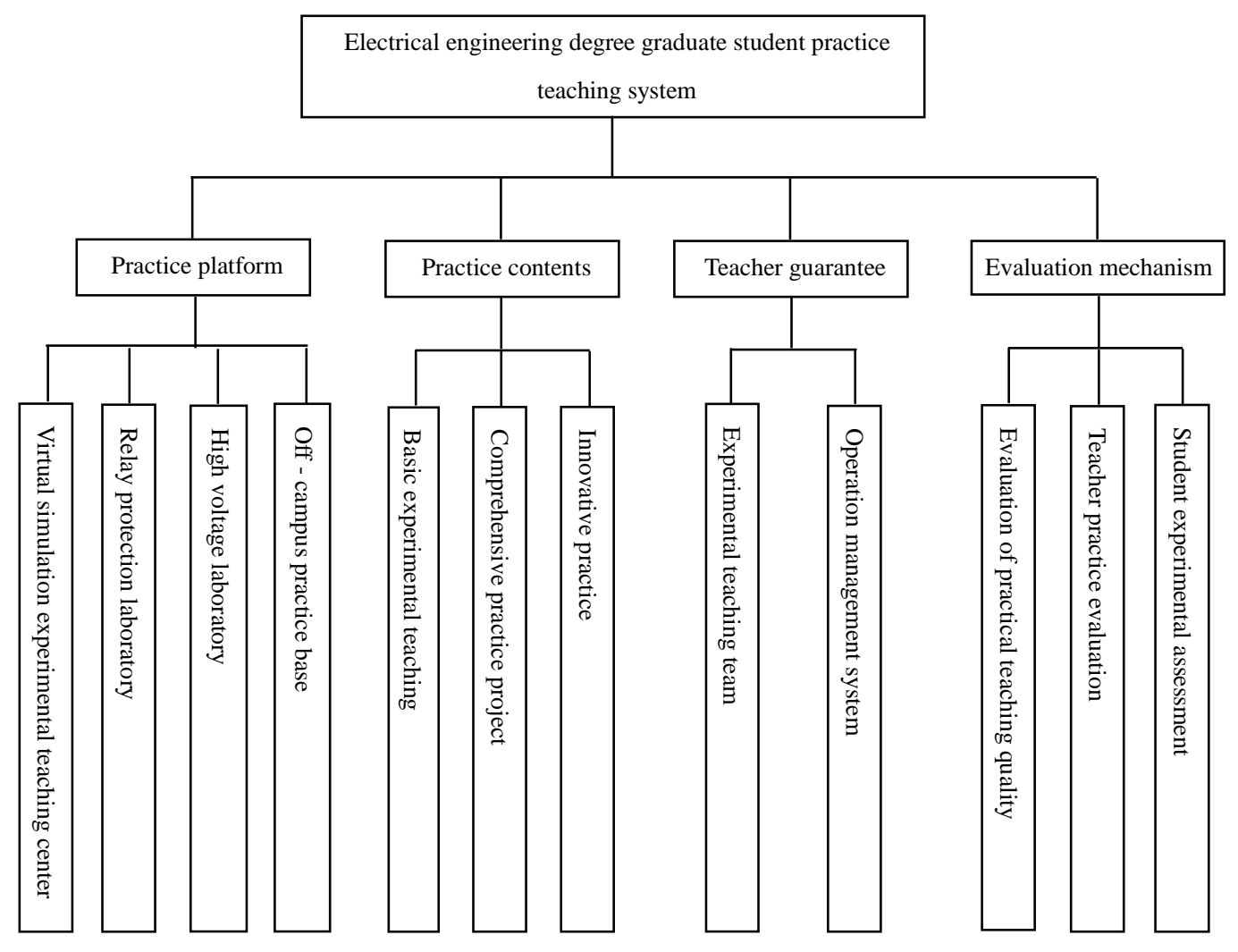

Fig.1. The practice teaching system structure diagram for electrical engineering degree graduate students

\section{A. Practical platform}

The practical platform mainly includes provincial virtual simulation experiment teaching center, relay protection laboratory, high voltage laboratory and off-campus practice base. The center can realize the virtual simulation experiment or analysis of the power flow calculation, fault analysis, overhead line engineering design, reactive power planning optimization and distributed generation supply co-control of power grid with wind power and photovoltaic power generation. The level of practical teaching is effectively improved and the ability of students to master the knowledge is greatly enhanced. Our school establishes a stable production and research cooperation units with Liaoyang Zhongding
Electric Power Engineering Design Institute, Chifeng City Aohanqi Agricultural Power Company and many other enterprises. Off-campus practice base for students every year on-site internship, in the internship period, the senior technical and management personnel are part-time teachers for graduate students, that is more close to the needs of enterprises and greatly enhancing the professional degree graduate "professional" needs.

\section{B. Practice contents}

Practice content system refers to the specific, targeted teaching contents based on all the practical teaching parts set reasonably. It is the core in the practice teaching system and it 
mainly includes basic experimental teaching, comprehensive practice project and innovation practice. Electrical engineering degree teaching team based on years of practical experience, has established an integrated multi-level practice teaching content system. The hierarchical structure is shown in figure 2.

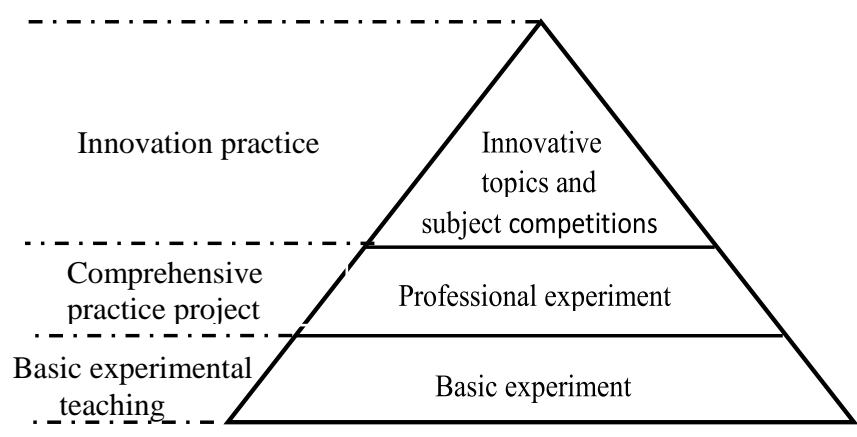

Fig. 2. Practice teaching content system hierarchy

Three levels of experimental content layer by layer, the difficulty increase, requiring improve and application technology level is progressive, to meet the needs of students at different levels and to improve student participation. The school encourages and guides graduate students to participate in the National College Students Electronic Design Competition, "Dongfanghong" intelligent agricultural equipment competition, mathematical modeling and other innovative practice contest, and in the contest the students have made excellent competition results. Therefore, by participating in the competition, the practice innovation ability of graduate students is greatly improved.

\section{Teacher guarantee}

Teacher guarantee includes experimental teaching team and operation and management system. It can effectively guarantee the practice of teaching orderly and effective development. At present, university recruitment pays more attention to academic level and scientific research achievements of applicants. However, the training goal of professional graduate students is to cultivate high-level applied and practical talents with strong professional ability and good professional accomplishment. Therefore, it is essential that we establish a teaching team with strengthen comprehensive ability, more practical experience, high technology level and reasonable structure. Now, there are 20 members in the practical teaching team of electrical engineering, including 5 professors, 10 associate professors, 5 lecturers, in which 15 members have doctoral degrees and 8 members have overseas study and research experience. Over the years, under the strong support of the College and the tireless efforts of the team members, the team achieved remarkable results in the professional construction, practice platform and practice curriculum system construction, innovative competition. Moreover, the mentor team takes the "double tutors" system combined with theoretical study and practical guidance. The students complete the main theoretical courses at school, and part of the course invited the power industry experts into the school. Professional degree graduate students are asked to practice at least six months in the corresponding practice department and complete the topic selection and implementation.
Operation management system mainly involves laboratory equipment management, teacher management, student management, experiment and safety management and so on. The Laboratories are open to postgraduates.

\section{Evaluation mechanism}

The evaluation mechanism can effectively reflect the implementation of the practice teaching system. It mainly includes three parts: evaluation of practical teaching quality and teacher practice evaluation, and student experiment assessment. Based on years of practical teaching experience our school establishes the corresponding practical teaching quality evaluation index system. Teachers' practice evaluation is evaluated by the students, the evaluation results are directly put into the teacher teaching quality assessment. So that it can avoid teachers' re-theory and light practice, and effectively improve the teacher's emphasis on practical teaching. The methods of students' experimental assessment are comprehensively assessed by experimental preview, experimental attendance, experimental completion, discussion records, experimental reports and other aspects.

\section{DeVelop a Wide RANGE OF Dissertation Standards}

Professional degree dissertation standards should be different from the academic degree dissertation standards, the latter focus more on theoretical research, but the former should reflect the diversity of practice. However, the practical application of professional degree is not a simple repetition of the production operation skills, but is the creative use of the knowledge in the industry. Therefore, the topic of professional dissertation should be derived from the application subject of the industry. Our school has developed the degree thesis standards with the electrical engineering professional characteristics. We encourage the students to use innovative knowledge to solve practical problems, whose results can be part of the thesis or academic application conditions.

\section{CONCLUSIONS}

Colleges and universities are paying more and more attention to innovation and practical ability which is the goal for full-time professional degree graduate students. Our school has made a series of practical teaching reform through the development of training programs, the construction of practical teaching system and the development of diversified degree thesis standards and other measures, and that has achieved significant results. However, the practice of teaching reform is a long-term process. Then, it need to explore and improve the practice of reform continuously, but also need schools, teachers and students to participate. Then, we can form a practice teaching mode with professional characteristics and effectively enhancing the practical ability of graduate students.

\section{ACKNOWLEDGMENT}

This work is supported by Research project of teaching reform of postgraduate education in Shenyang Agricultural University. Item Number: 2016-yjs-39. 2016-yjs-48. 


\section{REFERENCES}

[1] Wen Guanhua, Jiang Wenzhong, Chen Hongliang, “ Do good jobs of professional practice, to ensure that full-time professional degree graduate students training quality,” Degree and Postgraduate Education, vol.5, pp. 1-4, Augest 2010(In Chinese).

[2] Gu Yueye, Ye Bingliang, "The Construction of the Cultivation Mechanism of Innovative and Practical Ability of Graduate Students," Education Review, vol.2, pp. 104-106, Feburary 2016(In Chinese).
[3] Chen Yanhui, Li Yong, "Reform and Practice of Cultivating Mode of Graduate Students,” Continuing education research, vol.4, pp.118-120, 2016(In Chinese). 